\title{
Quality of Vision of Presbyopic via Progressive Additional Lens (PALs)
}

\author{
Nur Aresya Ahmad Najmee, Noor Halilah Buari, \\ Rabiatun Mujari, Muhammad Irwan Rahman \\ Optometry, Faculty of Health Sciences, Universiti Teknologi MARA, \\ 42300 Puncak Alam, Selangor, Malaysia \\ aresyanajmee@puncakalam.uitm.edu.my
}

\begin{abstract}
The number of presbyopia with inadequate correction is increasing worldwide which surely decreased the visual satisfaction. A survey was conducted to study the level of vision satisfaction between the quality of vision and symptoms reported by progressive addition lens (PALs). Sixty questionnaires were mailed to the (PALs) wearers aged between 40 years and above from Universiti Teknologi Mara (UiTM) Vision Care. The strongest correlation was between the quality of vision at intermediate viewing with total satisfaction on seeing grocery shelves and computer screen $p<0.001$. PALs wearers priority and needs should be considered in selecting the appropriate lens design for required tasks.
\end{abstract}

Keywords: level of satisfaction; quality of vision; multifocal lens; progressive additional lens

eISSN 2398-4279 @ 2018. The Authors. Published for AMER ABRA cE-Bs by e-International Publishing House, Ltd., UK. This is an open access article under the CC BY-NC-ND license (http://creativecommons.org/licenses/bync-nd/4.0/). Peer-review under responsibility of AMER (Association of Malaysian Environment-Behaviour Researchers), ABRA (Association of Behavioural Researchers on Asians) and CE-Bs (Centre for EnvironmentBehaviour Studies), Faculty of Architecture, Planning \& Surveying, Universiti Teknologi MARA, Malaysia.

DOI: https://doi.org/10.21834/ajqol.v3i13.171 


\subsection{Introduction}

Presbyopia is the most common physiological changes that occurred in adult eyes and expected to impact the quality of life in billions of people worldwide (Patel \& West, 2007; Chu, 2010). According to Laviers et al.,(2009), presbyopia is projected to impact 1.04 billion of people of which 517 million were left inadequately fixed. McDonnell et al., (2003) also claimed that the association of presbyopia have an adverse impact towards the life of United States population. Young eyes can quickly focus on near or distant objects. However, the ability diminished towards old age (Werner et al., 2000). According to Helmholtz's theory, presbyopia arose from the gradual loss of elasticity of the crystalline lens as the ciliary muscle and choroid become less efficient with age. Progressive degeneration combined with inadequate illumination, as light affects the human vision Wahab \& Zuhardi (2013), standard size print will soon diminish. The onset of presbyopia is considered to occur when the amplitude of accommodation has decreased to 5.00D or less (Grosvenor, 2007). As the amplitude of the accommodation diminished, the range of clear vision at near will also reduce due to the disturbance and difficulties in more frequent or demand near vision tasks.

A self-administered questionnaire by the National Eye Institute of Refractive Error Quality of Life was conducted and found that inadequate optical correction to the presbyopics has given adverse effects on their health-related quality of life. (Chu, 2010; Malinovska \& Majerova, 2015). The optical correction by spectacles is one of the effective solutions to remediate presbyopia. It remains as the most shared and cost-effective presentation worldwide (Marmamula et al., 2013). Prescribing reading additions based on patient's age would be the most successful method to determine correction addition required for the presbyopics (Leary \& Evans, 2003). Nevertheless, the use of progressive addition lens (PAL) is the ideal spectacle correction for presbyopia due to the property less distortion, which can provide a continuous progression in power for clear vision at all distances (Lynn, 1998). The property of progressive lens on PALs, enables a continuous clear vision at a distance, intermediate and near in which the dioptric power will gradually increase along the lens surface from the upper to the lower portion (Odjimogho, 2004)

\section{0 Literature Review}

The rate of quality of vision provided by the progressive addition lens (PALs) for the presbyopic was $90 \%$ and more in term of acceptance and comfortability (Hons, 2008). The high acceptance rate can be due to the elimination of imaginary lines and jumping images in which reduce the sudden change in the prismatic and increase the comfortability of the wearers (Walsh, 2001). Younger patients have achieved more comfortable fit compared to older patients. This condition may due to the more natural adaptation of the early presbyopic as compared to the late presbyopic agreed by Lynn (1998), where the multi-design lens scored the highest in quality of vision in the way of adaptation and patient satisfaction.

Although bifocal lenses were known for more appreciation in near field of view, however progressive lenses have given a very high success rate, $(97 \%)$ since the 1970 s (Gime, 2008). Moreover, most of the multifocal candidates chose PALs compared to bifocal design (Spaulding 1981; Lynn, 1998). The line on bifocals is not particularly attractive for 
presbyopes, especially to the younger patients. Yet, PALs offered a desirable additional power without the lines and ledges that fundamentally 'blend' the transition between distance and near zones (Meister \& Fisher, 2008). The ability to alter the dimension from the distance to intermediate and near were also influenced the high comfortability with PALs wearers. It represented the overlapping of multiple individual focal points, where each has their range of clear vision, which provides a single, broad expanse of clear vision from infinity to near distance (Gispets, Pujol, \& Vilaseca, 2011). Hence, clear vision is possible to some extent at all distances and indeed increased the quality of vision (Walsh, 2001).

Even though PALs is the ideal spectacle correction for presbyopia, however, the perfection of multi focal lenses were based on the optics of the lenses, the fit of the frame and the position wear including eyes and head movement for visual tasks at different viewing distances and patients. Restriction of the optical zone has been one of the significant problem complaints from the wearers as it caused difficulty in reading at both intermediate and near distance (Spencer \& Ciuffreda, 2002). This restriction may lead to the increment of prismatic effect at the lateral side and the frequency of the compensatory head movement for clear vision. Thus, patients need to view the appropriate part of the lens to obtained clear. Peripheral astigmatism will also present induced by the continuous change in power through the lens. PALs wearers may be aware of the lateral image blur that can adversely affect the successes of the adaptation process (Mok, Chung, \& Kwok, 2011). Moreover, most of the PALs wearers complained of vertigo and dizziness when changing gaze horizontally (Suemaru, Hasebe, \& Ohtsuki, 2008).

\subsection{Methodology}

A cross-sectional survey design was used with the collection of data of sixty respondents aged between 40 years old and above from UiTM Vision Care (optometric clinic and practice in Universiti Teknologi MARA). Subjects who wear progressive addition lens for other reasons such as myopia or accommodation were excluded from this research. The respondents were selected from patients' records and enlisted using convenience and availability sampling method. Patients' records were obtained by accessing their archived receipt of progressive additional lenses (PALs) purchased from UiTM Vision Care from February 2014 to February 2015.

A questionnaire was adopted from The Ohio State (DA1-B59/08, p. 4217, Feb 1999) to evaluate the satisfaction level of visual performance based on the respondents' daily activities. There were three parts of the questionnaire; namely (1) demographic details, (2) respondents feedback, and (3) symptoms reported by the PALs wearers.

The questionnaire was given via email, post and by other types of communication services. Demographics questions were developed to collect the respondents' information. Questions regarding visual performances at distance viewing, intermediate viewing and near vision with the total satisfaction of progressive additional lens (PALs) prescribed were calculated using a Likert scale. The Likert scale has been used as it is a simple, reproducible, quick and reliable in measuring the patients" satisfaction level (Hiraoka et al., 2009). The questionnaires had 10-point Likert responses scale for part (1) and (2) ranging from 0-10 
which represented as "totally unacceptable" to "excellent" respectively. Except for part (3) the scale range was a bit different, Likert response 0-10 was declaimed as "extremely bad" to "none" respectively. The scores were converted into percentages, the higher the rate, the level of satisfaction respondents using the PALs was assumed as increased. Total satisfaction of PALs wearer was determined by adding all responses in part (2) which give a total score of 100.

All data were analysed using SPSS software version 21.0. The descriptive data were shown regarding the mean and standard deviation. Satisfaction level was analysed using linear regression to determine the correlation between the qualities of vision with total satisfaction. As for the relationship between quality of vision and associated symptoms with total satisfaction, Spearman rank correlation was used. Findings with a $p$-value $<0.05$ were considered to be statistically significant.

\subsection{Results and Discussion}

All of the respondents have healthy eyes with a normal range of corrected vision. Hence, high qualities of vision and high levels of patients' satisfaction were most appreciated after the prescription of the progressive additional lens (PALs). Results were based on the quality of vision at the different viewing area and the symptoms reported after the application of PALs. Figure 3.1 and Figure 3.2 shows the mean value for symptoms reported and the quality of vision at the different viewing areas with the use of progressive additional lens respectively.

The mean value provided by the symptoms is indirectly proportional towards the satisfaction value. The highest reported symptoms related to the use of PALs lenses were blurry vision with a mean of $7.07 \pm 2.60$. In contrast, the mean value for the quality of vision is directly proportional to the satisfaction value. The highest mean is seeing grocery shelves at intermediate viewing $(7.27 \pm 1.84)$

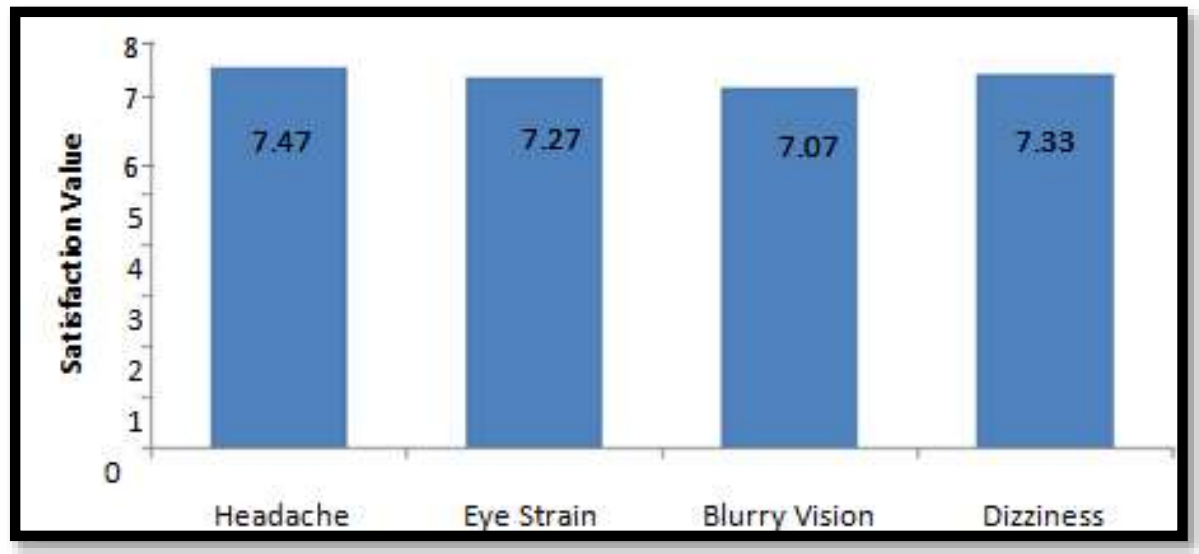

Figure 3.1: Mean symptoms reported associated with PALs 


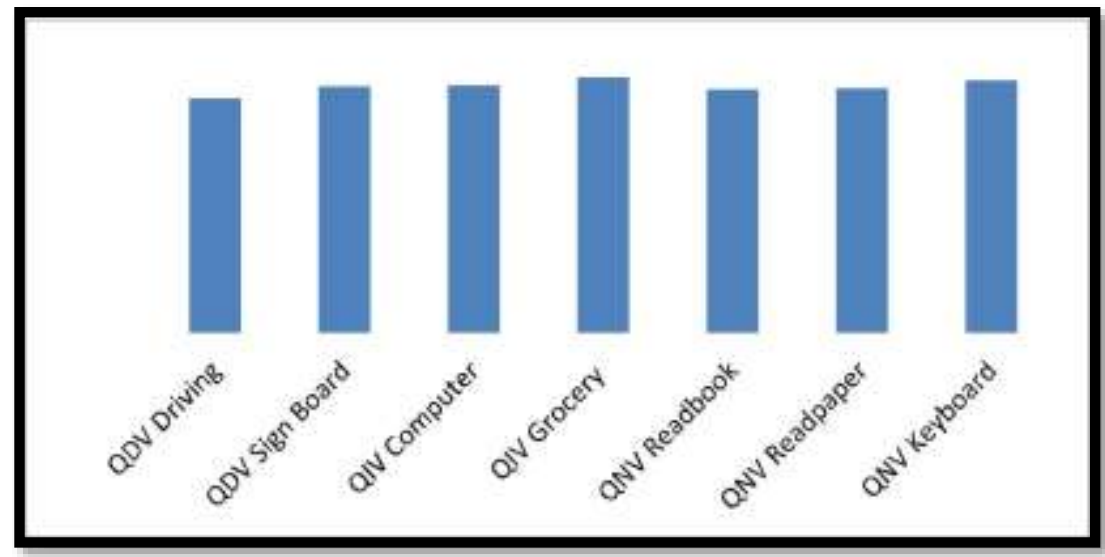

Figure 3.2: Mean quality of vision at the different viewing area.

\subsection{Symptoms and Total Satisfaction}

There were no statistical significant difference between the mean rating of each symptoms, and the correlation between each symptom and their total satisfaction, analysed by Spearman Correlation. The summary on the correlation of symptoms with quality of vision related with progressive additional lens was shown in Table 3.1

Table 3.1: : Summary on the correlation of the symptoms.

\begin{tabular}{lll}
\hline \multicolumn{1}{c}{ Symptoms } & Regression $(\mathbf{r})$ & p value \\
\hline Headache & 0.369 & 0.045 \\
Eye strain & 0.475 & 0.008 \\
Blurry vision & 0.701 & 0.000 \\
Dizziness & 0.437 & 0.016 \\
\hline
\end{tabular}

Most PALs wearers reported being comfortable with their lenses as the data obtained shows the least of complaints and symptoms with the high level of satisfaction. Blurry of vision is the most noticeable symptom that lowered the level of total satisfaction and showed the most positive regression lines among others. Nonetheless, a high correlation was recorded between the symptoms reported with the total satisfaction ( 0.7 and above) with the PALs dispensed. This indicates most wearer can use their PALs without any significant visual problems in their daily activities.

Poor adaptation, changes of power profile in term of magnification, astigmatism or aberration along the PALs lines can be the main causes of blurry vision. A similar result is obtained from the quality of vision at distance viewing which shows the lowest satisfaction. This likely due to the optical design of the PALs as progressive additional lens require gradual changes of distance to near area which caused unwanted distortion through the lower lens periphery (Chu, 2010). 


\subsection{Quality of Vision at Different Viewing Areas and Total Satisfaction.}

The relationship between the quality of vision at the different viewing areas and the total satisfaction were obtained by using Spearman Correlation. The test revealed that the correlation between the quality of vision at intermediate viewing is the highest compared to others. Intermediate viewing in seeing computer monitor and seeing grocery shelves are highly correlated to the total satisfaction which was associated with higher level of quality of vision. Higher scores indicated a better clarity of the visual performance. Meanwhile, the correlation of quality of vision during driving showed the lowest in the ranking of total satisfaction. Nonetheless, it is positively correlated with the total satisfaction which is statistically significant, of $p<0.05$ (Table 3.2).

Table 3.2: Summary on the correlation of quality of vision at diferrent viewing areas.

\begin{tabular}{lll}
\hline Quality of Vision & Regression $(\mathbf{r})$ & p value \\
\hline At Distance & & \\
Driving & 0.574 & 0.001 \\
See signboard & 0.728 & 0.000 \\
\hline At Intermediate & & \\
See computer monitor & 0.844 & 0.000 \\
See Grocery shelves & 0.844 & 0.000 \\
\hline Near & & \\
Reading books & 0.803 & 0.000 \\
Reading paper at chair & 0.791 & 0.000 \\
See keyboard & 0.833 & 0.000 \\
\hline
\end{tabular}

Different viewing areas and tasks are the significant factors that affect the satisfaction level as people seek for best correction lenses to help in improving their visual acuity and quality of life. Measuring the variances at different viewing areas has proven to affect the visual task performance (J. Sheedy, Hardy, \& Hayes, 2006). Thus, patients should be knowledge of the different zones' widths and areas across the lens to satisfy their visual performances. The result has shown that the level of visual satisfaction was the highest at the intermediate compared to the distance and the near viewing. The intermediate viewing provides a clear vision non-stepwise and corresponds to the wide visual distance range. It dramatically enhanced the capacity of the visual field at that segment (Sugarman, 1994).

Moreover, the tasks that required respondents to use their lens in the intermediate zones demonstrated a positive linear regression line and higher correlation coefficient value. This result corroborates with Gispets et al., (2011) and Spencer \& Ciuffreda, (2002) where the stimulus becomes sufficiently cramp and precise to be felt within the definite field of the view at the intermediate channel. In that event, this will reduce the shift of the head movements and cause it to become a more desirable yet closer match to the normal eye fixation magnitudes (J. E. Sheedy, 2004). Moreover, depth-of-focus in this area offers a better compromise in which sharper retinal images produced to be corresponding with the objects. Interestingly, related to this, it was reported that the performance of PALs is equivalent to the performance of single vision lenses (Spencer \& Ciuffreda, 2002). However, the main 
consideration of the PALs effectiveness at the intermediate viewing still needs to be related to the task itself.

The result of high satisfaction with significant positive linear correlation was also found at the near viewing on the tasks like reading a book on the table, reading the paper on a chair and seeing the keyboard. During reading, the eye does not move in an orderly manner. They pause, move backwards and jump from one point to another; hence required a high level of accommodation (Batemanazan et al., 2014). These findings support the prediction by the previous studies where reading involving size print would require the use of the clearest portion of the lens and the clarity of vision is ideal at the centre of the near zone (Lynn, 1998). High satisfaction can be barely assumed as most wearers were either able to tolerate well with the eye movement required during near task or adapt to the preferred lens design. Hence, this may happen due to the choices of the lens design for the suitable daily task were more toward near tasks compared to distance tasks (R.Cited, 2004).

As for the distance viewing such as driving, viewing an object at a distance are customarily paired with other vision disturbances; peripheral blur, unwanted astigmatism and distortion. Even though progressive additional lens (PALs) were reported to be more comfortable than the bifocal lens, however, most of them complain of distortion at the peripheral vision Han et al. (2011). Activities such as driving or walking by using progressive additional lens caused vision appear to oscillate at the sides (Ellison, 2012). These scenarios were due to the aberration and unwanted astigmatism at the peripheral section of the lens while making the higher visual demand (Spencer \& Ciuffreda, 2002). Peripheral astigmatism in the progressive lens has been found to be significant in its axis and magnitude (Hendicott, 2007). As follow, peripheral astigmatism can change the power along the vertex line of the PALs progression. Thus, wearers may experience astigmatism with the occurrence of blur when the eye moves toward the other different viewing areas.

\section{Conclusion}

Progressive additional lenses is the best option which represents the rigid multifocal correction for a significant share of the presbyopic population despite their limitation. Nonetheless, the improvement of the PALs design is consistently released as there was always a high demand for needs of the better understanding towards its progressive surface to enhance the quality together with wearers' adaptation and happiness (Pope, 2000). Thus, the result from this study can benefit the eye-care practitioners especially optometrists to improve the quality of servicing progressive additional lens by providing the information regarding the quality of vision that is positively correlated with the level of total satisfaction for progressive addition lenses.

Furthermore, progressive additional lenses require an appropriate design that matches with specific tasks and activities. Hence, the eye-care practitioners should always aware of the PALs wearers' priority and requirements in selecting the correct lens. This study can act as a stimulus for better research in the future especially in ophthalmic industry to develop and market PAL designs based on the wearers' specific visual needs and tasks. Additionally, due to the development of technology, there will be some enhancement in PALs designs, 
potentially to reduce the possible symptoms, yet increase the satisfaction level among PALs wearers in the future.

\section{Acknowledgement}

The authors wish to thank UiTM Vision Care and Faculty of Health Sciences, Universiti Teknologi MARA (UiTM) for permission to conduct the study and to all participants in the study.

\section{References}

Batemanazan, V., Jaafar, A., \& Salehuddin, K. (2014). A Comparative Study on the Eye Movement Patterns in Malay- English bilingual readers. Procedia - Social and Behavioral Sciences, 118, 229-234. https://doi.org/10.1016/j.sbspro.2014.02.031

Boroyan HJ, Cho MH, Fuller BC, Krefman RA, McDougall JH, Schaeffer JL, Tahran RL. (1995). Lined multifocal wearers prefer progressive addition lenses. J Am Optom Assoc. 66(5):296-300

Chu, B. S. (2010). The impact of presbyopic spectacles and contact lenses on driving performance.

Community Eye Health. (2006). How to prescribe spectacles for presbyopia, 19(57), 12-13.

Cited, R. (2004). (12) United States Patent, 2(12).

Ellison, A. (2012). Prismatic displacement effect of progressive multifocal glasses on fall risk in elderly people.

Gime, A. (2008). Influence of vision distance and lens design in presbyopic user preferences, 38, 1-8. http://doi.org/10.1016/j.ergon.2007.07.006

Gispets, J., Pujol, J., \& Vilaseca, M. (2011). Task oriented visual satisfaction and wearing success with two different simultaneous vision multifocal soft contact lenses, 4(3), 76-84.

Grosvenor, T. P (2007). Primary Care Optometry 5th Edition. Elsiever Health Sciences. Philadephia, USA.

Han, Susan C., Graham, A. D., \& Lin, M. C. (2011). Clinical Assessment of a Customized Free-Form Progressive Add Lens Spectacle, 88(2), 234-243.

Hiraoka, T., Okamoto, C., Ishii, Y., Kakita, T., Okamoto, F., Takahashi, H., \& Oshika, T. (2009). Patient Satisfaction and Clinical Outcomes After Overnight Orthokeratology, 86(7), 875-882.

Hendicott, P. L. (2007). Spatial perception and progressive addition lenses.

Hons, S. W. F. (2008). OPTOMETRY Progress in the spectacle correction of presbyopia. Part 2: Modern progressive lens technologies, (May), 251-264. http://doi.org/10.1111/j.1444-0938.2008.00246.x

Hsu, W., Liu, Y., \& Cheng, Y. (2012). Design, fabrication, and metrology of ultra-precision optical freeform surface for progressive addition lens with B-spline description. http://doi.org/10.1007/s00170-012-3901-1

Laviers, H. R., Omar, F., Jecha, H., Kassim, G., \& Gilbert, C. (2009). Visual Psychophysics and Physiological Optics Presbyopic Spectacle Coverage, Willingness to Pay for Near Correction, and the Impact of Correcting Uncorrected Presbyopia in Adults in Zanzibar, East Africa, 1234-1241. http://doi.org/10.1167/iovs.08-3154

Leary, C. I. O., \& Evans, B. J. W. (2003). Criteria for prescribing optometric interventions: literature review and practitioner survey, (November 2002), 429-439. 
Lynn, J. (1998). Progressive addition spectacle lenses: Design preferences and head movements while reading.

Malinovska, O., \& Majerova, H. (2015). Typhlotechnics for Persons with Visual Impairment and Quality of Life. Procedia - Social and Behavioral Sciences, 171, 438-441. https://doi.org/10.1016/j.sbspro.2015.01.144

Markovits, A., Reddix, M., O"Connell, S., \& PD Collyer. (1995). PAL"s increases the combined zone of near and intermediate correction and eliminate visible lines in the lens (Fig. 1). This intermediate zone of changing power (narrow, clear area in PAL lens, Fig. 1), is referred to as the transition channel. The spheric.

Marmamula, S., Ravuri, L. V. C. S., Boon, M. Y., \& Khanna, R. C. (2013). Spectacle Coverage and Spectacles Use among Elderly Population in Residential Care in the South Indian State of Andhra Pradesh, 2013, 12-17.

McDonnell, P. J., Lee, P., Spritzer, K., Lindblad, A. S., \& Hays, R. D. (2003). Associations of presbyopia with visiontargeted health-related quality of life. Archives of Ophthalmology, 121(11), 1577-1581. https://doi.org/10.1097/00132578-200404000-00020

Meister, D. J., \& Fisher, S. W. (2008). Progress in the spectacle correction of presbyopia. Part 1: Design and development of progressive lenses.

Mok, A. K., Chung, C. S., \& Kwok, T. W. (2011). A simple clinical test for the perception of progressive addition lens peripheral image blur. A pilot study, 4(1), 30-34.

Pope, D. R. (2000). Progressive Addition Lenses: History, Design, Wearer Satisfaction and Trends. OSA TOPS Vol. 35 Vision Science and Its Applications, 35, 342-357.

Patel, I., West, S. K., West, S. K., \& Ophthalmology, E.-M. P. of P. (2007). Presbyopia: prevalence, impact, and interventions.

Community Eye Health, 20(63), 40-1. Retrieved from http://www.ncbi.nlm.nih.gov/pubmed/17971909\%5Cnhttp://www.pubmedcentral.nih.gov/articlerender.fcgi?artid=P MC2040246

\section{S.E Odjimogho. (2004). SURVEY ON PROBLEMS ASSOCIATED WITH THE USE OF PROGRESSIVE ADDITION} LENSES (PAL), 11, 16-19.

Savio, G., Concheri, G., \& Meneghello, R. (2011). Parametric Modeling of Free-Form Surfaces for Progressive Addition Lens, 167-176.

Sheedy, J. E. (2004). Progressive addition lenses--matching the specific lens to patient needs. Optometry (St. Louis, Mo.), 75(2), 83-102. https://doi.org/10.1016/S1529-1839(04)70021-4

Sheedy, J., Hardy, R. F., \& Hayes, J. R. (2006). Progressive addition lenses - Measurements and ratings. Optometry, 77(1), 23- 39. https://doi.org/10.1016/j.optm.2005.10.019

Spencer, L. W., \& Ciuffreda, K. J. (2002). Assessing Visual Performance with Progressive, 79(8), 502-505.

Spaulding DH., (1981). Patient preference for a progressive addition multifocal lens (Varilux2) vs a standard multifocal lens design (ST-25). J Am Optom Assoc. 52(10):789-94.

Suemaru J1, Hasebe S, Ohtsuki H. (2008) Visual symptoms and compliance with spectacle wear in myopic children: double-masked comparison between progressive addition lenses and single vision lenses. Acta Med Okayama. 62(2):109-17. 
Ahmad Najmee, N.A., et.al. / Asian Journal of Quality of Life (AjQoL), 3(13) Sep/ Oct 2018 (p.150-159)

Walsh, G. (2001). The products we rely on - Part 5, 35-40.

Wahab, M. H. A., \& Zuhardi, A. F. A. (2013). Human Visual Quality: Art Gallery Exhibition. Procedia - Social and Behavioral Sciences, 101, 476-487. https://doi.org/10.1016/j.sbspro.2013.07.221

Werner, L., Trindade, F., Pereiera, F., \& Werner, L. (2000). Physiology of Accommodation and Presbyopia. Arquivos Brasileiros De Oftalmologia, 63(6), 503-509. https://doi.org/10.1590/S0004-27492000000600011 